\title{
Assisted living in rural areas: aging in blurred landscapes
}

\author{
Bodil H. Blix, Torunn Hamran \\ Centre for Care Research North, Department of Health and Care Sciences, Faculty of Health Sciences, UiT The Arctic University of \\ Norway, Tromsø, Norway
}

\begin{abstract}
Here, we explore the experiences and practices of care in the context of assisted living facilities (ALFs) in rural areas from the perspectives of family members, health care professionals, and senior citizen interest group representatives. Specifically, we focus on the potential for ALFs to safeguard and unify the health care policy ambitions of equity, quality, and aging in place. Focus group interviews with health care professionals and interest group representatives and individual interviews with family members were conducted in largely rural Norwegian municipalities. Providing high-quality health care services in people's homes remains challenging, particularly in rural areas. ALFs have been introduced as a compromise, a home away from home. In rural areas, ALFs are typically localized in community centers. ALFs are neither homes nor nursing homes, and residents possess varying and changing care needs. Several parties experience challenges with respect to safety, evolving care needs, and responsibilities. Moreover, the service allocation and user payment systems may undermine equity. This study indicates that health care authorities should evaluate whether prioritizing assisted living is still suitable for the aging population in rural areas and beyond.
\end{abstract}

\section{Introduction}

The Norwegian welfare state is based on the principle of universalism, which implies that all health and welfare services should be provided equitably to all cit-

Correspondence: Bodil H. Blix, Centre for Care Research North, Department of Health and Care Sciences, Faculty of Health Sciences, UiT The Arctic University of Norway, Tromsø, N9037 Norway.

Tel.: +47.77660682

E-mail: bodil.hansen.blix@uit.no

Acknowledgements: the authors are grateful for the editor's and the anonymous reviewers' constructive and clarifying comments on an earlier draft of this manuscript.

Key words: Assisted living; Rural health care services; Aging in place; Older adults; Dementia.

Contributions: the authors contributed equally.

Conflict of interest: the authors declare no potential conflict of interest.

Funding: this work was supported by The Research Council of Norway, Grant number 238146.

Received for publication: 13 September 2018.

Revision received: 23 March 2019.

Accepted for publication: 2 April 2019.

This work is licensed under a Creative Commons Attribution NonCommercial 4.0 License (CC BY-NC 4.0).

${ }^{\circ}$ Copyright: the Author(s), 2019

Licensee PAGEPress, Italy

Qualitative Research in Medicine \& Healthcare 2019; 3:47-57

doi:10.4081/qrmh.2019.7826 izens, regardless of age, gender, ethnicity, financial status, social status, and place of residency. ${ }^{1}$ Statutory services, such as home-based care and long-term care, are regulated through national juridical acts and public block-grant funding; however, a high degree of local autonomy exists with regard to the accommodation of services to local conditions, ${ }^{2}$ a principle termed local universalism or decentralized universalism. ${ }^{3,4}$ Norwegian governmental health care policy documents conceptualize predictability, familiarity, and continuity as key aspects of high-quality health care services. ${ }^{5}$ Norway is a country with a relatively small population of 5.2 million, ${ }^{6}$ of which approximately $20 \%$ resides in rural areas. ${ }^{7}$ There is a clear tendency of people moving from rural to more urban areas, particularly among younger people. ${ }^{8}$ Consequently, the average age of the population in rural areas is relatively high. Moreover, the overall Norwegian population is aging, with one in nine Norwegians currently aged 70 years or over, and this percentage is set to increase. ${ }^{6}$ The number of people with dementia in Norway has been estimated at 77,000, a percentage of the population fairly similar to the EU average of $1.55 \% .{ }^{9}$ Similar to other comparable countries, Norwegian health care authorities have conceptualized aging in place as an attainable and required goal for older adults and individuals with dementia. ${ }^{10,11} \mathrm{Si}$ multaneously, the number of assisted living facilities (ALFs) in Norwegian municipalities has increased. ${ }^{12}$

In this article, we explore the experiences and practices of care in the landscape of assisted living facilities for older people and people with dementia in rural areas from the perspectives of family members, health care professionals, and representatives of senior citizen interest groups. Specifically, we focus on the potential of ALFs in 
safeguarding and unifying the three health care policy ambitions of equity, quality, and aging in place.

\section{Landscapes of care, aging in place and assisted living}

Health geographers have introduced the concept landscapes of care as a framework for unpacking the complex relationships between people, places and care. ${ }^{13}$ Milligan and Wiles have suggested that experiences and practices of care are shaped by the interplay among socioeconomic, structural, and temporal processes. Moreover, they have noted the necessity of understanding the macrolevel governance and social arrangements, policies and place characteristics that operate at both national (and international) as well as interpersonal levels. ${ }^{13}$ This study demonstrates how experiences and practices of care in rural assisted living facilities are shaped, challenged, and negotiated within the frames of policies, ideals, geography, physical structures, and interpersonal relations.

Already in 1994, the health and social policy ministers of the Organisation for Economic Co-operation and Development (OECD) started to promote the concept of aging in place. ${ }^{14}$ Some definitions of aging in place stress the ability to live in one's own home, ${ }^{15}$ whereas other definitions emphasize the possibility of continuing to live in one's community. ${ }^{16}$ In Norwegian health care policy documents, aging in place is explicitly associated with a person's home: It is a goal to provide everybody the opportunity to live at home for as long as possible and to receive individually tailored services in their own homes [authors' translation]. ${ }^{11}$ The ideal of aging in place presupposes access to appropriate informal care and high-quality home-based health care services in people's homes. ${ }^{17}$ However, large geographical distances and insufficient staff competence pose challenges to the provision of sufficient high-quality home-based health care services, particularly in rural areas. ${ }^{18,19}$ Moreover, sociodemographic changes and mobility have reduced the possibility of informal care from family caregivers in people's homes. ${ }^{17,20}$ There is a growing awareness that an increasing number of older adults, including some with dementia, have extensive and complex needs that are incompatible with continuing to live in their own homes. ${ }^{21}$

When those in need of care can no longer manage at home or when sufficient health care services can no longer be provided at home, people must move. Thus, aging in place has been reinterpreted, ${ }^{22}$ and assisted living has been promoted as a home away from home ${ }^{21}$ a middle ground between homes and nursing homes, ${ }^{23}$ and a homelike environment that fosters respect for an individual's sense of autonomy, privacy, and freedom of choice. ${ }^{24}$

Just as the ideal of aging in place has gained ground in Norwegian health care policies, the number of people receiving health care services in their homes and in shortterm institutions increased between 2009 and 2015, whereas the number of people in long-term care institutions decreased. ${ }^{25}$ Simultaneously, the number of ALFs in
Norwegian municipalities has increased, and the number of local nursing homes in remote communities has decreased. ${ }^{12}$ In Norway, $11 \%$ of individuals over 80 years old reside in ALFs. ${ }^{26}$ Public statistics consider ALF residents to be registered as home dwelling. ${ }^{27}$

Although assisted living is growing rapidly, it lacks a common definition; therefore, differences with regard to ownership, auspices, size, and philosophy have been documented. ${ }^{28}$ Norwegian health care authorities have acknowledged the lack of a common legal definition of ALFs, stating that $[\mathrm{m}]$ unicipalities are not obligated to offer assisted living facilities to persons in need of health and care services, and no legal definition of assisted living facilities exist [authors' translation]. ${ }^{29}$ In other policy documents the line between ALFs and nursing homes is described as blurred: On the one hand, nursing homes are starting to resemble housing, while, on the other hand, current assisted living facilities are built in connection [to each other] and used as a supplement and an alternative to nursing homes [p. 42; authors' translation]. ${ }^{10}$ In fact, in Norway, the most distinctive difference between nursing homes and ALFs lies in the legal regulation of ALFs as independent housing. ${ }^{26,29}$ The majority of ALFs are served by home care services,${ }^{27}$ specified in contracts and paid for by the residents in the same manner as for ordinary home care services. ${ }^{29}$ A more limited number of ALFs are staffed on a 24-hour basis. ${ }^{29,30}$

\section{Purpose and research questions}

In this article, we explore the experiences and practices of care in the landscape of assisted living facilities for older people and people with dementia in rural areas from the perspectives of family members, health care professionals, and representatives of senior citizen interest groups. The following research questions guided the analysis:

From the perspective of older adults, family members and health care professionals, are ALFs adequate means for achieving the health care ambition of aging in place for people in rural areas? More specifically, are ALFs considered as people's homes? Are ALFs in rural areas consistent with the ideal of equity? Are ALFs in rural areas in line with the ideal of quality conceptualized as predictability, familiarity, and continuity?

\section{Materials and Methods}

\section{Study design}

To explore the expectations and experiences of health care professionals, family members and senior citizens, a qualitative research design combining focus group interviews and individual interviews was chosen. ${ }^{31}$ Focus group interviews were conducted with health care professionals and representatives of senior citizen interest groups (henceforth, senior representatives), and individual 
interviews were conducted with family members of individuals with dementia not living in nursing homes in northern Norway. Our understanding of a focus group interview is consistent with Barbour, who noted that any group discussion may be called a focus group as long as the researcher is actively encouraging of, and attentive to, the group interaction [...] ensuring that participants talk amongst themselves rather than interacting only with the researcher (p. 2). ${ }^{32}$ Our purpose was to elicit a multiplicity of views and experiences; hence, focus group interviews represent a particularly suitable research approach. Considering the personal and potentially emotional nature of topics related to being a family member of a person with dementia and to safeguard the anonymity of people with dementia, we chose to conduct individual interviews with family members rather than focus group interviews.

\section{Ethics}

This study was approved by the Norwegian Center for Research Data. All participants provided informed consent to participate. The participants were informed of their right to withdraw from the study without stating a reason, and they were assured that confidentiality would be maintained. At the beginning of the interviews, the interviewer described the purpose of the interview and assured the participants of their anonymity.

\section{Participants and recruitment}

The study was conducted in areas with largely rural populations, i.e., municipalities with populations ranging from 900 to 3000 residing in municipality centers and several surrounding remote communities.

Five focus group interviews were conducted with health care professionals $(\mathrm{n}=23)$ in five municipalities. The single inclusion criterion for the focus group interviews was that the participants were involved in providing everyday care for users of local health care services, including the provision of care for residents in ALFs, which means that the participants were either registered nurses or licensed practical nurses. Their work experience ranged from seven to forty years in the public health care service sector, and all participants were women. The managers of local care services distributed informational material and consent forms to potential participants. Signed consent forms were returned directly to us in prepaid envelopes. Consequently, local managers had no information regarding who chose to participate in the study. After receiving letters of consent, we scheduled focus group interviews in the respective communities. The focus groups varied in size and composition, with the smallest group consisting of only two participants and the largest group comprising eight participants.

One focus group interview was conducted with senior representatives from one municipality $(n=5)$. To recruit par- ticipants, we contacted an individual known to possess extensive knowledge of local interest groups. ${ }^{33}$ This person was asked to distribute informational material and consent forms to seniors involved in the most significant senior citizen interest groups in the community from different geographical areas in the municipality using a purposeful sampling strategy. Senior citizen interest group representatives who consented to participate in the study returned signed consent forms directly to us in prepaid envelopes. After receiving signed letters of consent, we scheduled the focus group interview. The focus group for the senior citizen interest group representatives consisted of individuals involved in the local dementia association $(n=2)$, the senior association $(\mathrm{n}=2)$, or independently $(\mathrm{n}=1)$.

Individual interviews were conducted with family members $(n=11)$ of persons with dementia not living in nursing homes in five municipalities. The participants were recruited from those who participated in a survey study of family caregivers for people with dementia. ${ }^{34}$ In the survey, the participants indicated whether they were willing to participate in a qualitative interview. Written informational material and consent forms were sent to people in five municipalities. When signed consent forms were returned to us, we contacted the participants to schedule interviews. The family members included spouses $(n=4)$, sons $(n=2)$, daughters $(n=4)$, and grandchildren $(\mathrm{n}=1)$.

\section{Focus group interviews}

The focus group interviews with health care professionals were conducted in meeting rooms at local nursing homes or health care centers while the focus group interviews with senior representatives was conducted at a local hotel.

A broad topic guide was used in the focus group interviews. The topic guide for health care professionals included the following topics: district descriptions, service user descriptions (e.g., geographic distribution, age span, and networks), the establishment of contact between service users and health care services, experiences of offered services being rejected, experiences of requested services being unavailable, collaboration with families and other informal caregivers, and the distribution of responsibilities between informal caregivers and health care services.

The topic guide for the senior citizen interest group representatives included the following topics: descriptions of the senior associations and their members, the representation from different geographical areas and social groups in the municipality, their collaboration with the municipality administration and public health care services, and their involvement in the decision making, planning, and design of health care services.

All focus group interviews were digitally recorded, and both authors were present; one was responsible for asking questions and initiating group discussions while the other focused on observing and taking notes regarding 
group interactions and identifying new leads as they appeared in conversations. Immediately after each focus group interview, we discussed the interviews and wrote field notes; then, the interviews were transcribed.

\section{Individual interviews}

Based on a broad topic guide, the participants were invited to speak freely about the person with dementia, their own situations as family members, their involvement in care provision, their contact and collaboration with public health care services, and their thoughts on the future. The interviews were conducted in the participants' homes or workplaces. All interviews were digitally recorded and transcribed, and the first author (BHB) conducted all individual interviews.

\section{Thematic analysis}

This study was part of a research project investigating the use and nonuse of community health care services among home-dwelling older adults and family caregivers. Hence, a wide range of issues were covered in the topic guides for the focus group interviews and individual interviews, and a variety of health care services and living arrangements in addition to assisted living facilities were addressed in the total data corpus. The data set for this study was identified by our particular interest in ALFs, and it comprised the instances in the corpus where issues related to ALFs were discussed. ${ }^{35}$ ALFs were discussed in all focus group interviews and in five of the individual interviews (the family members of the six remaining interviewees lived in their own homes). Hence, the data set was extracted from six focus group interviews (one with senior representatives and five with health care professionals) and five individual interviews.

A thematic analysis, described by Braun and Clarke as driven by the researcher's theoretical or analytic interest in the area, represented a suitable approach because it tends to provide a detailed analysis of some aspect of the data (p. 84). ${ }^{35}$ The audio recordings were replayed, and the transcribed texts were reread several times. We examined each interview individually using a process that involved a purposeful search for and coding of segments related to ALFs. The search for patterns and contradictions in the data set was a recursive back-and-forth movement between the data set and the coded segments. In the next phase, the codes were collated into potential themes and subthemes. Then, the themes were revised and named. This process resulted in the following main themes: Capacity and geography; Blurred landscapes; and Local and everyday adjustments. The main theme Blurred landscapes included the sub themes Home-like but not home; Blurred lines between ALFs and nursing homes; The complex nature of responsibilities in ALF landscapes; and Uncertainties concerning evolving care needs in ALF landscapes.

\section{Results}

\section{Capacity and geography}

The health care professionals and senior representatives presented ALFs as a pragmatic solution to the mismatch between people's care needs and the extent of services that is possible to provide in people's homes. This mismatch was partially presented as a result of the increasing need for care of people with dementia, as stated by one senior representative:

The home care services have become more devel-

oped. And most people wish to stay in their own

homes for as long as possible. But with regard to

people with dementia, it is necessary. Eventually.

They can't stay at home. They don't manage.

However, this mismatch was more often presented as a result of large geographical distances and the capacity issues in home care services, as outlined in the following statement from a health care professional:

If people live in [name of local community] and need much help...50 or 60 kilometers away... we have to say that we cannot manage. The capacity is too low. Then, we have to find other solutions. So, those who live far away get an apartment here in the [municipality] center. An assisted living facility.

In other words, the primary driver for moving to ALFs was not necessarily the service users' comprehensive care needs. Rather, large geographical distances and economic curtailments were presented as the driving forces. Hence, people in the remote areas of municipalities were particularly affected, as demonstrated in the following description from one of the focus group interviews with health care professionals:

About ten years ago, it was decided that services in the evenings and at night should only be provided in the area around [the municipality center]. Still, the economy allowed us to provide some services in remote areas. But not anymore. [...] We'll have to encourage people to apply for assisted living facilities in this area. [...] The assisted living facilities around here... there are perhaps 40 people living there. Most of them are from rural areas. [...] They could have stayed at home if we could drive there.

The final statement indicates that aging in place is particularly challenging in remote areas, leaving service users with extensive care needs in such areas no other choice but to move into ALFs in the municipality center. This point was also suggested by the senior representatives:

There has been a tendency that at least those who don't live close to the [municipality] center are strongly encouraged to move into a living facility here. Because the nurses have other things to do besides driving around the municipality. That's my impression. If you live quite close and are not in need of much care, then... But if you are in need of care, the tolerance for letting you live at home is low. 
The service users' needs for care and capacity/geographical issues were not ascribed an equal value as reasons for moving into an ALF. As a pragmatic solution to the imbalance between the services needed and the services capable of being provided, ALFs were presented as more legitimate when the mismatch could be ascribed to the service users' needs rather than aspects of the health care services or the geographical context. This point was demonstrated in the following statement from one of the focus group interviews with health care professionals:

It's sad when you have to move to the [municipality] center because your home is too far away. [... ] It's completely different if you have to move because you need more help. But if the only reason is... if you could have continued to stay at home if you lived closer to the center... if you have to move because of that...

Notably, neither geographical distances nor capacity issues were discussed by any of the family members interviewed in this study.

\section{Blurred landscapes}

\section{Home-like but not home}

In Norwegian health care policies, ALFs are defined as people's homes. Nonetheless, the family members expressed unease with defining an ALF as a home:

Even though the assisted living facilities are defined

as a home... It's not what I think of as a home.

That's the place where you lived and grew up.

Home... for my father, home is the house he built...

our home. That. But, of course, this is... this is his

home now. [...] But that's home. But... well... I have

thought... But, of course, this is his home.

This daughter demonstrates that home is a word that carries several connotations. The home is simultaneously a physical structure (a house), a personal idea, and a place of one's affection..$^{22}$ For her, the ALF does not convey all three meanings of the word home. A home is closely associated with a local community (the place where you lived and grew up). For people in remote areas of the municipalities, moving into an ALF in the municipality center involves moving away from their local communities.

Efforts are made to make ALFs home-like and to appear as homes rather than as institutions. Typically, ALF buildings are smaller, with private rooms or apartments and common spaces for residents. Nonetheless, ALFs did not necessarily appear as homes to some residents. One family member noted the following:

The rooms are nice. They have a small kitchen. The intention was that they should cook for themselves. Coffee and stuff like that. But it didn't happen. 'Cause she didn't... Well, she soon became very... Probably, she felt that she should be served when she is in an institution. You can't do things yourself there because it's not yours.

This daughter associated her mother's passivity with a lack of feeling ownership of her apartment (it's not hers) and the feeling of living in an institution. Additional examples of family members experiencing that the ALF environment restricted their leeway were observed, as expressed by one spouse:

I've been there a few times, playing my accordion.

And it has been... well, it was a success. But... I'm

also... on the other hand, I'm afraid to... force my-

self on... I'm a little careful about that. [...] I'm a

little careful about walking in on the arenas of oth-

ers. [...] Well... there is a common space... that's

not mine. There are several... several... in that common space. And... I don't know... I don't want to seem like I'm dominating in any way.

This husband was acutely aware that the ALF was his wife's home. Nonetheless, he felt that the ALF was somebody else's arena, and hence, not a place where he could entertain his wife with his accordion.

\section{Blurred lines between assisted living facilities and nursing homes}

The family members, health care professionals, and senior representatives all mentioned the mismatch between the intentions and the realities of ALFs. ALFs appeared to be designed for a group of residents different from those who currently lived there. They were intended for healthy people, but the residents had comprehensive needs for care. To meet residents' extensive care needs, ALFs have ended up resembling nursing homes. The status of ALFs then became more of a matter of definition (on paper), as stated by one granddaughter:

It's an assisted living facility. To live there, you

should be quite self-reliant. But it's more like a

nursing home, even if it's not on paper.

The gradual evolution from ALFs to nursing homes as a consequence of the residents' comprehensive care needs and the lack of other alternatives was also articulated by the health care professionals:

$[A L F S]$ were never intended for people in need of care. [... When the ALF] opened in [the 1990s], the residents were quite healthy and managed to cook for themselves and so on. Take a shower. But gradually they needed more care. Some of them were sent to [the nursing home], but it doesn't work like that because [the nursing home is full]. So, the ALF is more like a nursing home now. But the building is not designed for that.

Both the health care professionals and senior representatives suggested that ALFs are inappropriate for people with dementia. The senior representatives were particularly concerned regarding the safety of residents with dementia:

People have disappeared from the ALF and almost frozen to death in winter. In the neighboring municipality, people have gone outside and frozen to death at least twice. 
Similar concerns were also raised by the health care professionals.

One senior representative also questioned the competence of ALF staff with regard to people with dementia:

There should be health care professionals for the people with dementia. Fine, they come there as residents. They need food and care. But they also need health care professionals who know how to handle people with severe dementia. It's something more than forgetting which day it is or the names of visitors. Having health care professionals who know how to make life easier for people with dementia, not only how to provide daily care, is a matter of quality of life.

The health care professionals acknowledged that ALFs were not optimal for people with dementia but, rather, were used as a consequence of a lack of alternatives:

It's obvious. There are too few placements for people with dementia compared to the need. It's a dementia unit here. It's full. And those who cannot stay there or at the nursing home come here, to the assisted living facilities. It's an open environment where lots of people come and go. And the people with dementia sit there, perhaps pulling down their pants or urinating in a corner. It's terrible for the person with dementia. But also for the others sitting around watching.

\section{The complex nature of responsibilities in assisted living facilities landscapes}

The ambiguous position of ALFs in the continuum between homes and nursing homes may affect family members' and health care professionals' perceptions of responsibility, as demonstrated in the following description from a focus group interview with health care professionals:

I've heard several times from relatives that... for example, a daughter who says that we in the home care services are responsible for the person. That's troubling. [...] Particularly in ALFs. It's their homes.

In this context, the health care professionals could experience situations in which the residents' families ascribed responsibilities to them reaching far beyond their formal duties:

Some relatives expect us to take responsibility for far more than we are supposed to. For example, if the person is going to the hospital. Arranging the travel and being an escort. Many [relatives] believe that we fix it. And we used to do that, previously. But we have been told that it's not our responsibility. We are not supposed to do it. But we still do it, for some [residents], because they have no resources and no relatives.

However, the health care professionals' responsibilities could also be self-ascribed:
Yes, it is our [responsibility] because they are incapable of taking care of themselves. That's it. They are completely in need of care. They need help from us for care, or they can perhaps help with some guidance. But they are incapable of living on their own, which was the intention for such apartments in the first place.

This health care professional was acutely aware that the status of ALFs as homes had implications for the autonomy of residents and, consequently, the responsibilities of health care professionals. Nonetheless, this awareness was overruled by the fact that the residents were completely in need of care and incapable of living on their own.

For the family members, responsibilities could appear complex and confusing, as expressed by one daughter:

I simply don't know who her contact person is. I know nothing about that. [...] I don't know who to consult. There are lots of nurses. I don't know who is who. Who works in home care services and who [works at the nursing home]. My mother belongs to the home care services. So, I confuse them with those working at... I tend to believe that everybody in that office works there. But, obviously, they don't. When I give messages, I'm not sure if they get them. I have asked several times about her medication. I realize that the licensed practical nurses who work there do not know.

In this municipality, the ALFs and the nursing home were localized in the same building but were served with separate staff. The ALFs were served by home care services, whereas the nursing home had separate staff. For this daughter, the complex and confusing organization and division of responsibilities (I don't know who is who) compromised her opportunities for involvement in decisions regarding her mother (I don't know who to consult).

Concerns regarding the staffing of ALFs were also raised by the senior representatives. However, rather than ambiguous responsibilities, their concerns regarded the potential negative impacts of a changing and mobile staff for people with dementia:

The staff rotates continuously. We tried to tell [the managers] that if you read about people with dementia, you learn that what they need is stability the same people to relate to. But the leaders believed that their staff needed to rotate in order to be familiar with [all the different units in the care services]. Those who work in the ALF belong to the home care services, so they can't only be in the ALF.

\section{Uncertainties concerning evolving care needs in assisted living facilities landscapes}

For some family members, the transitions between levels of care appeared to be predictable and logical, as demonstrated in this son's response to the interviewer's queries regarding his father's opportunities for continued residency in the ALF in the face of increased care needs: 
I guess so. But I believe they perceive the nursing home as an alternative if the person is... reaching a certain need for care. That's next door. So, they can simply put him on a stretcher and roll him along the asphalt, and then, he is in another place. That's my impression - without taking it for granted. My impression is that's how things work. Eventually, they end up in the nursing home if they need a certain amount of care.

However, several family members expressed uncertainty with respect to the futures of individual residents, as demonstrated in the following statement from a daughter:

Well, we hope that he can stay here. That they don't move him to... down to the sick ward. Because here he... he knows those who work here. We have talked about it... he is allowed to stay here if he gets ill... sick... he is allowed to stay. Because the last week my mother was alive, she was moved down there... to the sick ward. And that was... They couldn't do anything other than give her palliative medication. She could have had that here. She could have stayed in her own room and... spent the last days... not in a cold... impersonal room down there. [...] So, we hope that ... he can stay here. This is his room, and it has been his room for the last few years... so he can stay here. Similar concerns were also expressed by the senior representatives. One of them, whose late spouse had to move into an ALF when the local nursing home was closed down, stated the following:

They told me that he would receive the same services in the ALF as he did in the nursing home. And that he could stay there for the rest of his life. Of course, within reason with regard to other illnesses. But, eventually, they told us that he couldn't [stay there] because he couldn't stand on his own legs. I felt it was paradoxical and sad. [...] I understand, of course, it was challenging. But I told them that they had promised that he could stay there. They told me that they were not sufficiently staffed. But, okay, since I nagged, they allowed him to stay.

These statements demonstrate dilemmas and uncertainties resulting from the discrepancy between the intentions and staffing of ALFs, on the one hand, and the residents' changing and evolving care needs, on the other hand.

\section{Local and everyday adjustments}

At the community level, the mismatch between the needs of the population and the intentions and staffing of ALFs could eventually result in the shutdown of ALFs, as demonstrated in the following example narrated by a health care professional:

Earlier, the municipality also had a care center in [remote area] with seven apartments intended for the elderly. Eventually, it was empty because no services were provided there, at least in the begin- ning. They didn't receive any help in the evenings or on weekends. People said that there was no point moving to the apartments. They would rather stay at home or move to an institution. Then, we had staff there for a period, and they received help in the evenings and on weekends. But it stopped. Too expensive for the municipality, I guess. And the result was that the care center was sold.

Apparently, this particular ALF filled a nonexistent need. The potential residents, who were healthy enough to live in the ALF, preferred to stay in their own homes. Meanwhile, those who needed more comprehensive services (including evenings and weekends) would rather live in a nursing home.

In other municipalities, local adjustments were made to meet the health care service needs of the population. For example, in one municipality, ALFs were simply used for more urgent purposes, as described by one health care professional:

For periods, the ALFs were empty. The apartments were empty. We used them for short-term nursing home placements.

Although ALFs are formally defined as residents' homes, the interviewed health care professionals provided examples of local ad hoc adjustments compromising residents' control and involvement in decision-making. For example, in one municipality, apartments rented by one person could be used as double rooms when there were rooming shortages:

The apartments have one room and a living room with kitchen. But they have taken... One person lives in the bedroom and another in the living room and

kitchen. There are two people in each apartment!

In some municipalities, the ALFs and nursing homes were located close to each other or even in the same building. All care and other expenses were included for the nursing home residents, whereas allocated care services were specified in contracts for the residents in the ALF. One health care professional describes adjustments made to reduce any potential inequities resulting from the different systems for service user payments and the service allocation for the nursing home and ALF residents:

Let me give you a classic example. Today, the weather was beautiful. And I figured I would make waffles and bring all the residents outside. And for the ones on short-term care, it's all inclusive. But for the residents in the assisted living facilities, it's not. Because they have [a certain amount of] allocated services and hours. But we don't think like that. No! We spend hours with them. And they can have dinner, if they wish to.

The senior representatives also expressed concerns regarding the potential for inequities inherent in the two different systems for user payment and service allocation. They were particularly concerned about the establishment of ALFs at the expense of local nursing homes and that 
the subsequently increased costs for individual residents would become a barrier to help-seeking:

In the new assisted living facility, there was a new model for payment. You pay according to the size of your room and the common spaces. You pay per square meter. And you pay for food, you pay for domestic help, you pay for laundry. You have to pay for everything. And when everything was added up... The politicians who had decided did not know how much it was. It was more than the minimum pension. [Interviewer: Do you think that this made people stay in their own homes longer?] Absolutely! Even with compensation from the municipality's so-called relief fund, it's wrong. It's wrong that you end up on poor relief in old age. That you don't have enough money to pay for yourself, so the municipality has to pay for you. It is wrong. People should not be made [economically] dependent.

In this particular municipality, local adjustments in the form of the establishment of a relief fund were necessary to prevent any potential inequities resulting from the establishment of ALFs in the municipality center and the corresponding shutdown of local nursing homes in the surrounding remote areas.

\section{Discussion}

The results from this study indicate that assisted living in rural areas challenges the Norwegian health care policy ambitions of equity, quality, and aging in place. Some of these challenges are closely associated with the rural context, whereas others may be relevant beyond this context.

\section{Aging in place}

Aging in place is an ambiguous concept. ${ }^{16,36}$ The concept may refer to aging in one's own home. ${ }^{15}$ The ideal of aging in place conceptualized as aging in one's own home faces challenges resulting from a mismatch between the care needs of home-dwelling people and the extent of home-based services that is possible to provide in people's homes. This mismatch may be particularly evident in rural areas characterized by large geographical distances between municipality centers, where health care services are typically located, and remote communities..$^{37,38}$ The health care professionals and senior representatives interviewed in this study acknowledged this mismatch and confirmed that it was a driver for moving older people with comprehensive care needs into ALFs. The results from this study indicate that ALFs are not considered as homes by the residents, health care professionals or family members. In previous research, aspects such as autonomy, self-identity, close social relationships, mutual respect, comfort, involvement, and security have been identified as crucial for experiences of homeness in ALFs. ${ }^{23}$ Our data included examples illustrating challenges particularly with respect to autonomy and involvement (e.g., the use of residents' apartments as double rooms when there were rooming shortages) as well as security (e.g., examples of people disappearing from ALFs during winter). Moreover, there were examples illustrating challenges with respect to maintaining close social relationships (e.g., the husband hesitating to play his accordion for his wife because he considered the ALF as someone else's arena).

A second meaning of the concept of aging in place is aging in one's community. ${ }^{16}$ Previous research has demonstrated that the move to ALFs in a community where one has important place attachments assists with the transition and process of becoming at home. ${ }^{23}$ In rural areas, the localization of ALFs in municipality centers challenges the ideal of aging in place, conceptualized as aging in one's community. When ALFs are located in municipality centers, moving from one's own home to an ALF may imply moving away from one's local community. Wiles et al. have demonstrated that older adults emphasize aspects such as a sense of attachment or connection, including aspects such as attachment to place, when given the opportunity to consider what makes a living environment acceptable, ${ }^{16}$ and seniors in rural communities have reported concerns related to stress and mental strain related to being moved from their communities to receive care. ${ }^{37}$

A third meaning of the concept of aging in place has been suggested, that is, the ability to remain in the same living facility, whether it is one's own home or an ALF, until one dies. ${ }^{39,40}$ The results from our study indicate that assisted living also challenges the ideal of aging in place, conceptualized as aging in one place. The family members and senior representatives expressed concerns regarding residents' future prospects with respect to continuing to live in an ALF in the face of increased care needs. Previous studies have demonstrated that residents are often unable to reside in ALFs until they die..$^{39-41}$

\section{Quality}

Norwegian ALFs vary greatly with regard to how they are staffed; some provide 24-hour staff, while in others, care is provided by home care service personnel. For the municipalities included in this study, the ALFs were served by home care services. The results from this study indicate that ALFs may challenge the ideal of quality care, conceptualized by Norwegian health care authorities as being characterized by predictability, familiarity, and continuity. ${ }^{5}$ The issue of continuity was raised by the senior representatives, who expressed concerns regarding the possible negative impacts of shifting and rotating staff on residents with dementia. They also questioned whether home care service staff possessed the necessary competence to provide care for people with dementia. Moreover, issues regarding safety, particularly for ALF residents with dementia, were discussed by both the health care professionals and senior representatives. Safety and staff 
competence were not questioned by the family members. However, it was apparent that the staffing of ALFs (who is who) was enigmatic and, hence, neither predictable nor familiar for some family members.

Scholars have noted that assisted living is no longer the place it was designed to be. [A]ssisted living has become the new nursing home (p. 216) ${ }^{24}$ and a discrete node that services residents similar to those in [nursing homes] and in a similar fashion (p. 108). ${ }^{42}$ In the present study, the health care professionals, senior representatives, and family members all noted that the ALFs were largely designed for a group of residents different from those who are currently inhabiting them. Moreover, the differences between ALFs and nursing homes were minimal with respect to the care needs of residents and the level of care provided. The blurred line between ALFs and nursing homes may pose a challenge to the principle of familiarity. The family members' accounts indicated that the ALF environments, resembling more traditional institutions, restricted the leeway of both residents and family members. Moreover, the ambiguous status of ALFs as neither homes nor nursing homes challenges the principle of predictability. Both the health care professionals and family members reported confusion and disagreements regarding responsibilities. The health care professionals experienced situations in which family members expected them to take on responsibilities that, formally, were not theirs, whereas the family caregivers expressed uncertainty regarding what they could expect from health care services. Health geographers have pointed to the increased blurring of boundaries between institutional and non-institutional settings and the redistribution of responsibility for care between statutory, voluntary and private bodies, friends and families (p. 745). ${ }^{13}$ The uncertainties regarding future care needs and the ability to continue residing in ALFs in the face of increased care needs expressed by both the family members and senior representatives are also at odds with the principles of predictability and continuity. The use of ALFs as short-term nursing home placements and the use of ALF apartments as double rooms to compensate for rooming shortages reported by the health care professionals in this study could be framed as accommodations of nationally regulated services to local conditions. ${ }^{3,4}$ Nonetheless, such adjustments challenge the principle of predictability. Moreover, the necessity of permitting such accommodations constitutes a reason for reflecting on whether the national policies prioritizing the establishment of ALFs over nursing homes are in line with the population's service needs. ${ }^{26}$

\section{Equity}

Assisted living may pose a challenge to the Norwegian health policy aim of providing equitable health care services to all citizens regardless of age, gender, ethnicity, financial status, social status, and place of residency. Notably, the systems for funding and service user payment are dif- ferent for people living in ALFs and those living in nursing homes. According to Norwegian legislation, municipalities can demand up to $75 \%$ of the monthly income from people living in nursing homes, and all care and other expenses (with the exception of clothes and personal items) are included. People living in ALFs typically pay rent and other expenses, and the care services provided are specified in contracts based on assessments of individual needs. ${ }^{26}$ Norwegian health care authorities have acknowledged that such financial and structural variations may result in inequities: Different sets of rules may result in different expenses for the same services, depending on whether the municipalities offer placement in institutions or the services are provided in owned or rented housing [p. 51, authors' translation]. ${ }^{10}$ Despite the ad hoc adjustments by health care professionals in their everyday practices and the establishment of systems for economic support reported in this study, the different systems for funding and service user payment challenge the principle of equity. Moreover, the results from this study indicate that older adults' possibilities to age in place are affected by the place of residency as a result of large geographical distances and the localization of health care services, including home care services and ALFs, in municipality centers.

\section{Conclusions}

The existing ideal of aging in place faces challenges resulting from the characteristics of both health care service users and health care services as well as challenges arising from geographical contexts. In rural areas associated with large geographical distances from municipal centers, such as the communities included in this study, the provision of high-quality health care services in people's homes remains particularly challenging. Consequently, ALFs have been introduced as a compromise: $a$ home away from home. In rural areas, where ALFs are typically located in community centers, this home may be particularly far from home. However, ALFs are neither homes nor nursing homes, and this middle ground between homes and nursing homes faces challenges related to safety, evolving care needs, and responsibilities which are being experienced by several parties. These challenges are at odds with health care policies stating that predictability, familiarity, and continuity are among the most significant aspects of high-quality services. The national policies stimulating the establishment of ALFs may also be at odds with the ideal of equity since different systems for service allocation and user payment are operated in ALFs and nursing homes.

As a measure to safeguard the necessary competence of community health care services, the Norwegian government has encouraged intermunicipal collaborations. Moreover, a process of fusing smaller municipalities into larger units, the so-called local government reform, has been initiated. ${ }^{43}$ In the years to come, it will be necessary 
to monitor whether such initiatives promote or counteract the ideals of aging in place, equity, and quality health care for older adults in rural areas. Furthermore, health care authorities should evaluate whether the continued prioritization of assisted living is suitable for managing the challenges arising from an aging population in rural areas and beyond. Future studies should assess to what extent ALFs are actually cost-effective, meet the needs of residents and family members, and are places health care professionals can provide high quality care. Moreover, the involvement of residents, family members and health care professionals in the decision making, planning and design of future community-based care will contribute to the establishment of care and living arrangements that are in line with the needs of the population served.

This study involved relatively few participants and was conducted in a specific geographical context. Moreover, assisted living facility residents were not included in the study. The results must be read and applied considering these limitations. Two researchers with different clinical, theoretical and methodological expertise were involved in the research process and thereby provided rich opportunities for investigator triangulation in order to reduce the risk of biased decisions and interpretations ${ }^{44} \mathrm{We}$ have attempted to make the study interpretively rigorous by providing the readers with sufficient information regarding the context for our research and through the extensive use of quotations from the interviews. However, more research involving larger samples in other geographical contexts is necessary to extend our knowledge of assisted living. Importantly, future research should include assisted living facility residents.

\section{References}

1. Anttonen A, Sipilä J. Universalism in the British and Scandinavian social policy debates. In: Anttonen A, Häikiö L, Stefánsson K, eds. Welfare state, universalism and diversity. Cheltenham: Edward Elgar; 2012. pp 16-42.

2. Vabø M. Norwegian home care in transition - heading for accountability, off-loading responsibilities. Health Soc Care 2012;20:283-91.

3. Vabo SI, Burau V. Universalism and the local organisation of elderly care. Int J Sociol Soc Policy 2011;31:173-84.

4. Burau V, Kröger T. Towards local comparisons of community care governance: exploring the relationship between policy and politics. Soc Pol Admin 2004;38:793-810.

5. Norwegian Ministry of Health and Care Services. Helse- og omsorgsdepartementet. Meld. St. 29 (2012-2013) Morgendagens omsorg. [Report to the Storting (White Paper). Future care]. Oslo, Norway: Norwegian Ministry of Health and Care Services; 2013.

6. Statistics Norway. Key figures for the population. Oslo, Norway: Statistics Norway; 2018. Available from: https://www. ssb.no/en/befolkning/nokkeltall/population Accessed: March 8, 2018.

7. Statistics Norway. Population and land area in urban settlements, 1 January 2016. Oslo, Norway: Statistics Norway;
2016. Available from: https://www.ssb.no/en/befolkning/statistikker/beftett/aar/2016-12-06 Accessed: March 5, 2018.

8. Rogne AF, Syse A. Framtidens eldre i by og bygd. Befolkningsframskrivinger, sosiodemografiske mønstre og helse [Future elderly in cities and parishes. Population projections, socio-demographic patterns and health]. Oslo: Statistisk sentralbyrå [Statistics Norway]; 2017.

9. Alzheimer Europe. Norway. 213: The prevalence of dementia in Europe. Luxembourg: Alzheimer Europe; 2014. Available from: https://www.alzheimer-europe.org/Policy-inPractice2/Country-comparisons/2013-The-prevalence-ofdementia-in-Europe/Norway Accessed: August 2018.

10. Norwegian Ministry of Health and Care Services. Helse- og omsorgsdepartementet. Omsorg 2020 Regjeringens plan for omsorgsfeltet 2015-2020 [Care plan 2020 - The Norwegian government's plan for the care service field for 2015-2020]. Oslo, Norway: Norwegian Ministry of Health and Care Services; 2015. Available from: https://www.regjeringen.no/ en/dokumenter/care-plan-20202/id2410456/

11. Norwegian Ministry of Health and Care Services. Helse- og omsorgsdepartementet. Demensplan 2020 Et mer demensvennlig samfunn [Dementia plan 2020 - A more dementia-friendly society]. Oslo, Norway: Norwegian Ministry of Health and Care Services; 2015. Available from: https://www.regjeringen.no/en/dokumenter/dementia-plan2020/id2465117/

12. Jacobsen FF, Mekki TE. Health and the changing welfare state in Norway: a focus on municipal health care for elderly sick. Ageing Int 2012;37: 25-42.

13. Milligan C, Wiles J. Landscapes of care. Progr Human Geogr 2010;34:736-54.

14. OECD. Careing for frail elderly people: new directions in care. Paris: Organisation for Economic Co-operation and Development; 1994.

15. Fänge AM, Oswald F, Clemson L. Aging in place in late life: theory, methodology, and intervention. J Aging Res 2012;2012:547562.

16. Wiles JL, Leibing A, Guberman N, et al. The meaning of "aging in place" to older people. Gerontologist 2011;52: 357-66.

17. Tarricone R, Tsouros AD. The solid facts: home care in Europe. Geneva, Switzerland: World Health Organization; 2008.

18. Forbes DA, Morgan D, Janzen BL. Rural and urban Canadians with dementia: use of health care services. Can J Aging 2006;25:321-30.

19. Hasson H, Arnetz JE. Nursing staff competence, work strain, stress and satisfaction in elderly care: a comparison of homebased care and nursing homes. J Clin Nurs 2007;17:468-81.

20. Genet N, Boerma WG, Kringos DS, et al. Home care in Europe: a systematic literature review. BMC Health Serv Res 2011;11:207.

21. Maddox GL. Making a house a home. Gerontologist 2003;43:931-4.

22. Frank JB. The paradox of aging in place in assisted living. Westport, Connecticut: Bergin \& Garvey; 2002.

23. Cutchin MP, Owen SV, Chang P-FJ. Becoming "at home" in assisted living residences: exploring place integration processes. J Gerontol B Psychol Sci Soc Sci 2003;58:234-43.

24. Roth EG, Eckert JK. The vernacular landscape of assisted living. J Aging Stud 2011;25:215-24.

25. Helsedirektoratet. Analyse av utviklingstrekk i omsorgstjenesten 2016: Utviklingstrekk og endringer som skjer i sektoren [Analysis of trends in the care services 2016: Trends 
and changes in the sector]. Oslo, Norway: Helsedirektoratet, Norwegian Directorate of Health; 2017.

26. Daatland SO, Høyland K, Otnes B. Scandinavian contrasts and Norwegian variations in special housing for older people. J Hous Elder 2015;29:180-96.

27. Gabrielsen B. Færre eldre bor på sykehjem [Fewer older adults live in nursing homes]. In: Ramm J, ed. Eldres bruk av helse- og omsorgstjenester [Use of health care services among older adults]. Oslo - Kongsvinger: Statistisk sentralbyrå [Statistics Norway]; 2013. pp 93-100.

28. Hawes C, Phillips CD, Rose M, et al. A national survey of assisted living facilities. Gerontologist 2003;43:875-82.

29. Norwegian Ministry of Health and Care Services. Helse- og omsorgsdepartementet. Prop. 99L Proposisjon til Stortinget (forslag til vedtak) Endringer i pasient- og brukerrettighetsloven og helse- og omsorgstjenesteloven (rett til opphold i sykehjem eller tilsvarende bolig særskilt tilrettelagt for heldøgns tjenester - kriterier og ventelister) [Proposal to the Storting. Changes in the patients rights act and the health care services act (the right to nursing home placement or residence adjusted for round-the-clock care services - criterias and waiting lists)]. Oslo, Norway: Norwegian Ministry of Health and Care Services; 2015.

30. Daatland SO, Otnes B. Institusjon eller omsorgsbolig? [Institution or assisted living?]. Samfunnsspeilet [Statistics Norway] 2015;2017:15-22.

31. Lambert SD, Loiselle CG. Combining individual interviews and focus groups to enhance data richness. J Adv Nurs 2008;62:228-37.

32. Barbour R. Doing focus groups. London, UK: Sage Publications; 2007.

33. Blix BH, Hamran T. "When the saints go marching in": constructions of senior volunteering in Norwegian government white papers, and in Norwegian senior volunteers' and health-care professionals' stories. Ageing Soc 2018;38: 1399-428.

34. Moholt J-M, Friborg O, Blix BH, Henriksen N. Factors affecting the use of home-based services and out-of-home respite care services: A survey of family caregivers for older persons with dementia in Northern Norway. Dementia 2018;1471301218804981. [Epub ahead of print]. Available from: https://journals.sagepub.com/doi/full/10.1177/ 1471301218804981?url_ver=Z39.88-2003\&rfr_id=ori:rid: crossref.org\&rfr_dat $=$ cr_pub\%3dpubmed\#articleCitationDownloadContainer

35. Braun V, Clarke V. Using thematic analysis in psychology. Qual Res Psychol 2006;3:77-101.

36. Andrews GJ, Cutchin M, McCracken K, et al. Geographical gerontology: the constitution of a discipline. Soc Sci Med 2007;65:151-68.

37. Bacsu JR, Jeffery B, Johnson S, et al. Healthy aging in place: supporting rural seniors' health needs. Online J Rural Nurs Health Care 2012;12:77-87.

38. Bull N, Krout J, Rathbone-McCuan E, et al. Access and issues of equity in remote/rural areas. J Rural Health 2001; 17:356-9.

39. Ball MM, Perkins MM, Whittington FJ, et al. Managing decline in assisted living: the key to aging in place. J Gerontol B Psychol Sci Soc Sci 2004;59:S202-12.

40. Chapin R, Dobbs-Kepper D. Aging in place in assisted living. Philosophy versus policy. Gerontologist 2001;41:43-50.

41. Hawes C, Phillips CD, Holan S, et al. Assisted living in rural America: results from a national survey. J Rural Health 2005;21:131-9.

42. Zimmerman S, Gruber-Baldini AL, Sloane PD, et al. Assisted living and nursing homes: apples and oranges? Gerontologist 2003;43:107-17.

43. Kommunal- og moderniseringsdepartementet. Meld. St. 14 (2014-2015) Kommunereformen - nye oppgaver til større kommuner [Report to the Storting 14 (2014-2015) The Local Government Reform - New tasks for Larger Municipalities]. Oslo: Kommunal- og moderniseringsdepartementet; 2015.

44. Polit DF, Beck CT. Nursing research. Generating and assessing evidence for nursing practice. Philadelphia: Lippincott Williams \& Wilkins; 2012. 